\title{
Changes in the profile of inequality across Europe since 2005: austerity and redistribution
}

\author{
Markus P.A. Schneider* \\ University of Denver, Denver, CO, USA \\ Stephen Kinsella* \\ University of Limerick, Ireland \\ Antoine Godin* \\ Kingston University, London, UK
}

\begin{abstract}
We present two Gini-like inequality indices that provide a more nuanced picture of how the profile of inequality has changed across European countries since 2005. We use these indices to analyse the distributional changes that can be attributed to the push for austerity. We estimate the JV-indices for 24 European countries over 9 years, and then use this panel to analyse the distributional effects of the fiscal consolidation policies Europe endured after the 2008 crisis. We find that austerity increased income inequality in eurozone countries, but reduced income inequality in countries that do not use the euro as their currency. We uncover a significant new relationship between austerity policies and the tails of the income distribution, further suggesting that in the eurozone these policies on average amount to a redistribution from the bottom to the top.
\end{abstract}

Keywords: austerity, Europe, inequality, income distribution, Gini, Lorenz curve

JEL codes: $D 31, D 63, E 62, E 65, H 6$

\section{INTRODUCTION}

The dual objectives of this paper are to present two complementary inequality indices that provide a more nuanced picture of how the distribution of income is changing across European countries and to use the information that these indices provide to study the distributional changes that can be attributed to the push for 'austerity' across Europe in 2010. Following Blyth (2013a: 866-877), let us define austerity as cutting the state's budget to stabilize public finances, restoring competitiveness through wage cuts, and creating better investment expectations by lowering future tax burdens. Austerity is not simply fiscal consolidation, nor is it a static concept. Austerity is rooted in a dynamic conception of the economy as an evolving object with its own inter-temporal budget constraint. The objective of austerity is to inspire confidence amongst international investors that their investment will yield positive returns. The signal provided by the large drop in government expenditure or increase in

* Email addresses: markus.schneider@du.edu (Markus P.A. Schneider, corresponding author), stephen.kinsella@ul.ie (Stephen Kinsella), a.godin@kingston.ac.uk (Antoine Godin).

Received 29 February 2016, accepted 13 July 2016 
taxes is traded for increased investment as a result of this increased confidence, generating a so-called expansionary fiscal contraction.

As more and more attention is devoted to understanding how the size distribution of income is related to policy and business cycle changes, it is important to track distributional changes across the entire distribution. It is well known, for example, that the most frequently used summary measure, the Gini coefficient, is most sensitive to distributional changes near the mode of the distribution and this understates increasing inequality due to changes in the upper tail. The empirical work by Thomas Piketty and his many co-authors was path-breaking exactly because their focus on top income shares highlighted distributional changes that had gone largely unnoticed. More recently, Voitchovsky (2005) highlighted that it is 'the profile of inequality' - not just inequality per se - that matters for the future performance of an economy.

The measures for inequality at the bottom and inequality at the top used in this paper were proposed by Jantzen/Volpert (2012) (we will refer to them as the JV indices from here on) and are based on a very parsimonious Lorenz curve model. Both in terms of the data requirements and overall generality, our statistical approach for calculating these measures has advantages over discrete approximations or the fitting of complex parametric distributions. Yet together with an overall measure of inequality like the Gini, they provide a complete and nuanced summary of how the distribution of income is changing.

With respect to the distributional impact of austerity across Europe, we provide an expanded and more rigorous follow-up analysis to Schneider et al. (2016). Specifically, the calculation of the JV indices from Eurostat Statistics of Income and Living Conditions (SILC) data has been significantly refined while the number of countries for which we estimate them has been expanded. Furthermore, we include separate measures for cyclically adjusted spending and revenue from the Organisation for Economic Co-operation and Development (OECD) in addition to International Monetary Fund (IMF) estimates for changes in the cyclically adjusted primary balance. Using this data, we look at the impact of changes to a country's fiscal stance on the distribution of income, paying special attention to whether changes in public expenditures or revenues affect inequality at the bottom or top of the distribution.

\section{AUSTERITY IN EUROPE}

The central idea that captured the imagination of European policy-makers was that debtridden countries could not spend their way to prosperity. In the aftermath of the global financial crisis of 2008, many European countries (especially at the periphery) saw deficits soar and by 2010 there was a concerted push for 'the deliberate deflation of domestic wages and prices through cuts to public spending' (Blyth 2013b) as well as increased revenue through new taxes. Of course, the worsening fiscal position of countries like Spain had little to do with excessive spending and a lot to do with capital flight from the periphery in the aftermath of the financial crisis (see Boyer 2012; Zezza 2012). The contractionary effects of spending cuts and tax increases were minimized in public discussion while the virtues for 'business confidence' were highlighted. As so many have now pointed out, the 'confidence fairy' (Krugman 2010) never showed and the economic multipliers associated especially with spending cuts proved bigger than anticipated, resulting in the prolonged and still-ongoing economic slump hobbling Europe (Zezza 2012; Blyth 2013b; Guajardo et al. 2014).

While austerity tends to focus on cuts to the public sector and privatization, reductions in the social safety net spending, and reductions in worker security (especially via cuts to pension programs, see Table 1), it also includes a push to raise revenue. Especially in the peripheral countries, this included often regressive taxation via sales and excise taxes, VATs, and property taxes (see Table 2). Ortiz/Cummins (2013) offer a systematic review 
Table 1 Reforms to expenditures by country, 2009-2012

\begin{tabular}{|c|c|c|c|c|c|c|}
\hline Country & $\begin{array}{l}\text { Public wage } \\
\text { freeze/ } \\
\text { reduction }\end{array}$ & $\begin{array}{l}\text { Control } \\
\text { size of } \\
\text { civil service }\end{array}$ & $\begin{array}{l}\text { Savings } \\
\text { from } \\
\text { pensions }\end{array}$ & $\begin{array}{l}\text { Savings } \\
\text { from } \\
\text { health care }\end{array}$ & $\begin{array}{l}\text { Reduction of } \\
\text { other social } \\
\text { benefits }\end{array}$ & $\begin{array}{l}\text { Reduction in } \\
\text { public } \\
\text { investment }\end{array}$ \\
\hline France & & $x$ & $x$ & $x$ & & \\
\hline Germany & & & & & $x$ & \\
\hline Greece & $\times$ & $\times$ & $\times$ & $\times$ & $x$ & $\times$ \\
\hline Ireland & $\hat{x}$ & $x$ & $x$ & $x$ & $\hat{x}$ & $x$ \\
\hline Italy & $x$ & $x$ & $x$ & $x$ & $x$ & $x$ \\
\hline Portugal & $x$ & $x$ & $x$ & $x$ & $x$ & $x$ \\
\hline Spain & $x$ & $x$ & $x$ & $x$ & $x$ & $x$ \\
\hline $\begin{array}{l}\text { United } \\
\text { Kingdom }\end{array}$ & $x$ & $x$ & $x$ & $x$ & $x$ & $x$ \\
\hline
\end{tabular}

Source: International Monetary Fund (2012: table 4).

Table 2 Reforms to revenue sources by country, 2009-2012

\begin{tabular}{lllllllll}
\hline Country & $\begin{array}{l}\text { Incr. } \\
\text { pers. } \\
\text { income } \\
\text { tax }\end{array}$ & $\begin{array}{l}\text { Incr. } \\
\text { corp. } \\
\text { income } \\
\text { tax }\end{array}$ & $\begin{array}{l}\text { Incr. } \\
\text { capital } \\
\text { gains tax }\end{array}$ & $\begin{array}{l}\text { Incr. } \\
\text { soc. sec. } \\
\text { contr. }\end{array}$ & $\begin{array}{l}\text { Incr. } \\
\text { sales tax }\end{array}$ & $\begin{array}{l}\text { Incr. } \\
\text { sexcise } \\
\text { tax }\end{array}$ & $\begin{array}{l}\text { Incr. } \\
\text { prop. } \\
\text { tax }\end{array}$ & $\begin{array}{l}\text { Better } \\
\text { tax } \\
\text { compliance }\end{array}$ \\
\hline France & $\times$ & $\times$ & & $\times$ & $\times$ & $\times$ & & \\
Germany & & $\times$ & & & & & & \\
Greece & $\times$ & & & $\times$ & $\times$ & $\times$ & $\times$ & $\times$ \\
Ireland & $\times$ & & $\times$ & & $\times$ & $\times$ & $\times$ & $\times$ \\
Italy & $\times$ & $\times$ & $\times$ & $\times$ & $\times$ & $\times$ & $\times$ & $\times$ \\
Portugal & $\times$ & $\times$ & $\times$ & & $\times$ & $\times$ & $\times$ & $\times$ \\
Spain & $\times$ & $\times$ & $\times$ & $\times$ & $\times$ & $\times$ & $\times$ & $\times$ \\
United & $\times$ & & $\times$ & $\times$ & $\times$ & $\times$ & & $\times$ \\
Kingdom & & & & & & & & \\
\hline
\end{tabular}

Source: International Monetary Fund (2012: table 4).

of IMF Country reports from the pre-crisis period through projections for 2016, providing further specific detail regarding the adoption of austerity globally.

Some researchers suspect that the push for austerity really reflected an opportunistic salvo for a neoliberal policy agenda (Peet 2011; Bougrine 2012; Zezza 2012). ${ }^{1}$ Hence austerity also meant

withdrawing the state from demand management ... re-intensifying state intervention on the side of finance capital, through deregulation, privatization and de-unionization; weakening social democratic policies, like state provision of health and welfare benefits, student grants, income

1. Blyth (2013a) provides tacit push-back to the notion that the turn to austerity was purely opportunistic. Conversely, Ortiz/Cummins (2013) point out inconsistencies between the IMF's denouncements of austerity while giving orthodox pro-cyclical policy advice in the recommendations of specific country reports. 
supplements and pension funds and 'liberalization' of entire economies, as with open-border trade policies. (Peet 2011: 388)

Whether it was simply the ideologically seductive appeal of fiscal responsibility, the overbearance of Germany and its myopic devotion to export-led growth for all (Blyth 2013b), or simply the most recent thrust in the neoliberal policy agenda is somewhat immaterial. What matters is that the surprisingly broad policy consensus across Europe resulted in many countries trying to cut their public spending and/or introducing new taxes at roughly the same time. In this sense, the 2010 turn towards austerity presents a unique policy experiment for the continent. Coincident with this experiment was the availability and easy access of detailed distributional data for many European countries, and we take advantage of both to provide a baseline analysis of the impact of austerity on the distribution of income across a panel of European countries.

Past analyses have found that the general distributional impact of fiscal consolidation made up of these policy changes is unsurprisingly to increase inequality (see the empirical findings reviewed by Schaltegger/Weder 2014). ${ }^{2}$ Consistent with this finding, Zezza (2012) provides a coherent argument that the turn towards austerity implies a redistribution from workers to asset owners - from the bottom majority of the distribution to the top minority. This also connects to post-Keynesian authors like Stockhammer (2013) and Rada/Kiefer (2015) who have pointed out that a declining wage share can be expected to cause persistent aggregate demand problems. While we investigate the size distribution of income rather than the functional distribution, there is a clear way in which our results complement their arguments. ${ }^{3}$ Since we are able to discern where exactly the distribution of income is changing, we might more specifically expect that the positive relationship between fiscal consolidation and inequality is driven by increasing inequality at the top. We not only find this to be the case, but also uncover weak evidence that austerity decreases inequality at the bottom.

A tangentially related question is what the effects of such distributional changes might be on future growth. Neoliberal supporters of austerity argue that increased inequality at the top would boost the incentives of entrepreneurs, and a reduction in the size of the public sector means that there are fewer impediments in their way. Mankiw (2013) explicitly makes the case that greater inequality driven by top incomes increases private incentives and, via free markets, leads to efficient outcomes, though his case is unrelated to austerity in Europe. It might also seem that Voitchovsky's (2005) empirical results lend tacit support to this proposition: she finds that greater inequality at the top is indeed associated with faster growth over the period 1975-2000.

However, the case that there are positive incentive effects to growing inequality rests on numerous implausible assumptions, as Robert Solow (in Solow et al. 2014) points out in his response to Mankiw (2013). And Voitchovsky (2005) herself suggests that the effects of increased inequality in different parts of the distribution may have fairly unclear consequences for incentives. She summarizes the literature by pointing out that especially inequality at the bottom may have reduced positive incentive effects because they are offset by worker frustration and feelings of unfairness, and are associated with negative externalities due to increased antisocial behavior. Moreover, inequality at the top may

2. Schaltegger/Weder (2014) also show that the composition of the government matters and that coalition governments tend to mitigate the undesirable distributional impact better than either leftleaning or right-leaning governments.

3. Atkinson et al. (2011) also document that inequality has increased thanks to thriving top income shares across many countries since the late 1970s, while growth overall has remained subdued. The gains from growth have thus not been shared with large swaths of the population in many developing countries, while the business cycle has become more volatile as social safety nets have been dismantled. 
be associated with increased rent-seeking and economic inefficiency (see also Gordon/DewBecker 2007; Stiglitz 2012; 2016). Certainly the literature on austerity that has yet to uncover positive growth effects that might be attributed to either increased investor confidence' or better private incentives for top income earners, together with our results showing that austerity in the eurozone is associated with greater inequality at the top, raises serious doubts about positive growth effects of increased inequality - at least in post-crisis Europe.

Of course, the austerity experiment saw very different implementation across European countries, in part reflecting different countries' fiscal positions. Europe's largest economy and export giant, Germany, ran a primary surplus during the later 2000s and was able to commit to very little austerity. France also resisted many of the more aggressive changes despite continual (largely unwarranted) bad press about its fiscal position. Smaller countries considered to be peripheral - like Spain, Ireland, and Greece - found themselves running large deficits as capital fled back to the core after the financial crisis (Boyer 2012; Zezza 2012) and were less able to resist calls for reform. They were thus forced to implement much harsher austerity measures. ${ }^{4}$ The only counterexample to this characterization in our sample is the United Kingdom, where harsh austerity measures were adopted despite all - with severe consequences for its economy and population (Ginn 2013).

Much of this goes beyond the narrower scope of the present work, which only seeks to investigate the empirical relationship between austerity measures implemented by different European countries and the observed distributional changes across the entire income distribution. To that effect, we use the JV indices as complements to the Gini as our measure of inequality overall and run a panel data analysis for 24 countries from 2005 to 2014, and the results are suggestive for the discussion above. In the sections that follow, we spell out our methodology for estimating the JV indices of inequality from SILC data and our panel estimation strategy. After that, we discuss the results before making some largely speculative concluding remarks.

\section{METHOD}

The method for assessing inequality across the distribution used in this paper was originally proposed by Jantzen/Volpert (2012) and used recently by Schneider/Tavani (2016). It is based on the observation of approximate self-similarity in both the left and right tails of the observed income distribution. Self-similarity refers to the repeating pattern of inequality in subsequently smaller and smaller quantiles of either tail. For example, in the US about half of all income goes to the top decile of income earners, but the top 1 percent get about half of the top decile's share (so about a quarter of total income). Approximately half of what is going to the top 1 percent goes to the top 0.1 percent, and half of that appears to go to the top 0.01 percent (see Piketty/Saez 2006). This pattern is called right self-similarity and reflects power-law behavior in the upper tail of the distribution. The degree of inequality associated with the repeating pattern is reflected in the share of income going to the top percentile: do the top 1 percent capture half or only 40 percent of the share of income going to the top decile?

Jantzen/Volpert (2012) note a similar pattern of self-replication at the bottom (left) end of the distribution. They observe that in the US the bottom two quintiles together appear to be getting about a quarter of the share of income going to the bottom 80 percent

4. Kinsella (2012) provides an illustrative analysis of Ireland, showing that neither the recent experience nor the experience of the 1980s should justify holding it up as a poster-child of expansionary fiscal consolidation. A case bolstered by Perotti (2012). 
of income earners. The bottom quintile however receives roughly a quarter of what the bottom 40 percent capture, and the bottom decile gets roughly a quarter of the bottom quintile's share. This suggests that the observed distribution is also at least approximately left self-similar.

Based on these observations, Jantzen/Volpert (2012) propose a parametric Lorenz curve model that features asymptotic right and left self-similarity towards the extremes of the upper and lower tails respectively (their 'hybrid model' is among the family of Lorenz curve models discussed by Sarabia et al. 1999). Based on the parameters of this model, the authors propose two indices that capture the degree of inequality in the upper and lower tails of the distribution, $G_{1}$ and $G_{0}$ respectively. Specifically, $G_{1}$ is higher if the top 1 percent get half rather than only 40 percent of the top decile's income share - or the fatter the power-law tail gets. Similarly, $G_{0}$ is greater if the bottom decile gets a smaller portion of the bottom quintile's income share. With a minor modification to $G_{0}$ proposed in Schneider/Tavani (2016), both JV indices are Gini-like in the sense that they are based on the Lorenz curve and take values between 0 and 1 . However, $G_{1}$ and $G_{0}$ do not represent a decomposition of the Gini coefficient in that it is not possible to recover the overall Gini as a linear combination of the JV indices. In fact, the Gini coefficient is relatively insensitive to the distributional changes captured by either of these two indices.

The fact that our chosen approach is based on fitting a parametric Lorenz curve directly to the data has several appealing features. Given data on income shares captured by different population percentiles, this procedure is (i) easier than modified approximations for the Gini or other inequality indices, and (ii) more parsimonious than the common practice of fitting a very general parametric distribution to raw or binned data (see Jenkins 2009 for an example). Whether one uses the JV indices, entropy-based indices, or income shares should ultimately be unimportant as long as an appropriate set of indices is used to differentiate between distributional changes at the bottom or at the top. We appreciate, for example, that Voitchovsky (2005) characterizes the 'profile' of the income distribution using three ratios $-90 / 10,50 / 10$, and 90/50 - to capture exactly these kinds of differences. We believe our method is superior because it takes much more information about the very extremes of the upper and lower tails into account. After all, the main insight brought to light by Piketty/Saez $(2003$; 2006) and Atkinson et al. (2011) is that most of the action in terms of recent distributional changes is happening within the top decile!

\subsection{JV indices of inequality}

The two-parameter Lorenz curve model proposed by Jantzen/Volpert (2012) is given by equation (1), where $p$ and $q$ are the parameters of the model and $x$ is the cumulative population share whose share of all income is $L(x ; p, q)$. According to Sarabia et al. (1999), Jantzen/Volpert (2012), Schneider/Tavani (2016), and our own findings, this model fits observed income distributions very well for a number of countries.

$$
L(x ; p, q)=x^{p}\left(1-(1-x)^{q}\right)
$$

The Gini coefficient, $G$, as well as the JV indices, $G_{0}$ and $G_{1}$, can be calculated from the estimated parameters according to equations (2), (3), and (4) respectively. As noted above, the JV indices are based on the degree of inequality in the asymptotically self-similar right and left tails of the distribution. Note that $G_{1}$ is strictly decreasing in $q$ (consistent with a smaller exponent of the implied asymptotic power-law suggesting a fatter tail and thus greater inequality) while $G_{0}$ is a strictly increasing function of $p$. 


$$
\begin{gathered}
G=1-\frac{2}{p+1}+2 \frac{\Gamma(p+1) \Gamma(q+1)}{\Gamma(p+q+2)} \\
G_{0}=\frac{3 p}{p+2} \\
G_{1}=\frac{1-q}{1+q}
\end{gathered}
$$

The parameters $p$ and $q$ in equation (1) were estimated using Stata's $n l$ estimation command, and the inequality indices appearing as the dependent variables in our panel estimations were calculated according to the equations above. ${ }^{5}$

\subsection{Illustrative examples}

To make the kind of analysis that looking at the JV measures of inequality at the bottom and top more concrete, we would like to highlight some specific country cases. Given that our follow-up analysis is on the distributional impacts of austerity, it makes sense to pick countries that highlight the implementation of spending cuts in the name of deficit reduction and future growth, so we will use Spain and Greece as illustrative examples. Our guiding principle for these comparisons are the social welfare implications of distributional changes as outlined by Atkinson (1970) and generalized to take into account growth by Shorrocks (1983). What Atkinson (1970) showed is that if income is redistributed so that the new Lorenz curve lies strictly above the old one while average income per capita remained the same, then there would be a social welfare gain for any strictly concave social welfare function regardless of the implied degree of inequality aversion.

Thanks to Sarabia et al. (1999), this can be translated into dominance conditions of the estimated parameters in model (1). Specifically, if we let $\Delta p=p_{2}-p_{1}$ and $\Delta q=q_{2}-q_{1}$, then:

$$
L\left(x ; p_{1}, q_{1}\right) \geq L\left(x ; p_{2}, q_{2}\right) \text { if and only if } \Delta p \Delta q \leq 0 \text { and } \Delta p>0 \text { or } \Delta q<0 \text { or both. }
$$

But this leaves out the consideration of compensating growth taken up by Dollar et al. (2015), which is where the generalized Lorenz curve due to Shorrocks (1983) is very helpful. By rescaling the vertical axis to GDP per capita, the generalization allows us to use Lorenz curve comparisons when there were both distributional changes and growth. The underlying logic regarding welfare implications remains the same: if the new generalized Lorenz curve lies strictly above the old one, there was an unambiguous welfare gain - either due to growth or distributional changes or both.

Looking at Spain in 2008 compared to 2011 gives us an illustrative picture. In Figure 1, the right frame shows the Lorenz curve and it is discernible that the distribution in 2008 strictly dominates that of 2011, which is likely to be the result of 'reforms to ease firing and lay-offs, curb severance pay and limit collective bargaining rights' (Ortiz/Cummins 2013: 16). In addition, the economy contracted so that the generalized Lorenz curve for 2011 (left frame) also lies strictly below that of 2008. We can therefore claim that between 2008 and 2011, Spain's population experienced an unambiguous welfare loss due to both distributional changes and the contraction of the economy. Furthermore,

5. Raw parameter estimates and standard errors are available from the authors upon request. 

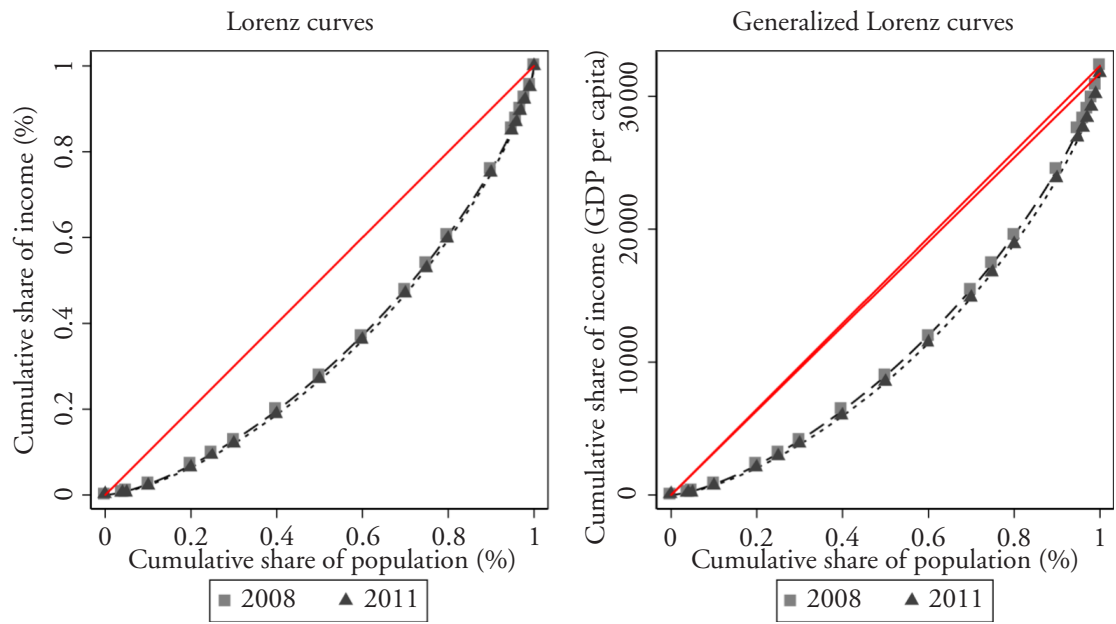

Figure 1 Changes in the Lorenz curve (right) and generalized Lorenz curve (left) for Spain, 2008 to 2011
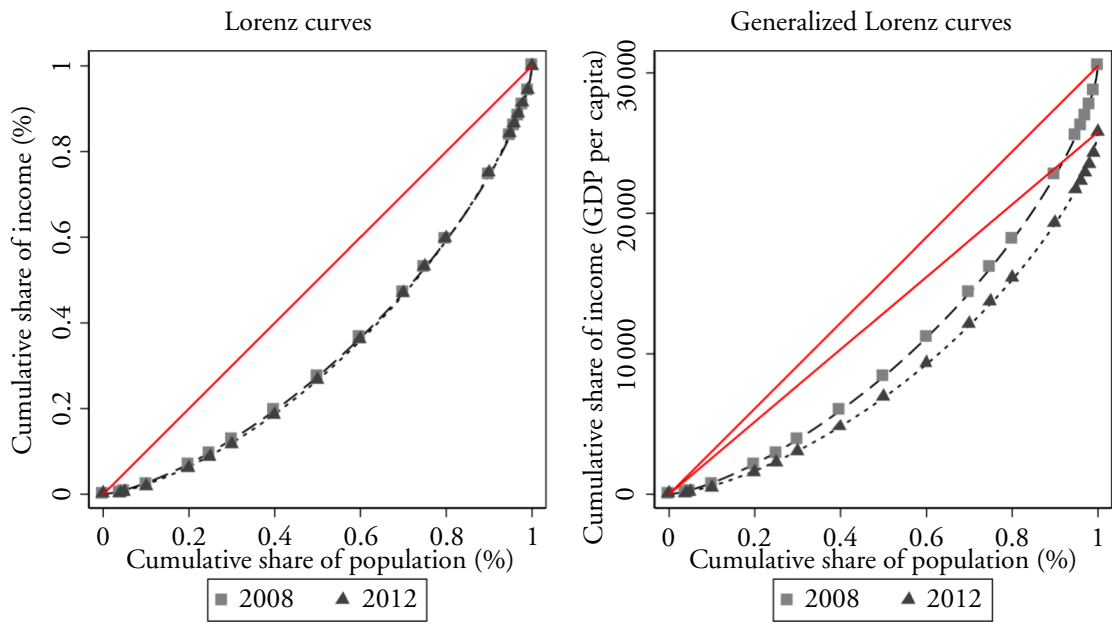

Figure 2 Changes in the Lorenz curve (right) and generalized Lorenz curve (left) for Greece, 2008 to 2012

our analysis shows that the distributional changes were driven by an increase in inequality at the bottom of the distribution.

By comparison, the distributional changes in Greece between 2008 and 2012 are somewhat ambiguous: there was rising inequality at the bottom, but a reduction in inequality at the top (see Figure 2). No clear assessment of the welfare implications of the distributional changes alone is possible. However, the economic contraction in Greece was much more dramatic, so that the generalized Lorenz curve for 2012 lies far below that of 2008 .

The Lorenz and generalized Lorenz curves for Ireland or Germany (not shown), provide interesting contrasts to those for Spain and Greece. Between 2008 and 2012, Ireland saw no 
notable distributional changes (mild increase in $G_{0}$ and a small decrease in $G_{1}$ ) and very little change in GDP per capita (still below 2008, but not far). In Germany, the distribution of income had changed little, but there was relatively strong growth, so that the generalized Lorenz curve for 2012 was everywhere above that of 2008. Instead of continuing country by country through their specific experiences in terms of distributional changes and growth patterns, we propose a simple statistical analysis to see if there are broader patterns of how austerity affected the distribution of income in different countries.

\subsection{Analysis of distributional effects of austerity}

As an application of why looking at distributional changes across the whole distribution - or the profile of inequality, as Voitchovsky (2005) put it - we look at changes in the cyclically adjusted fiscal positions of European countries and the effect of those changes on our distribution measures. We have a panel of 24 countries over 9 years for which we have estimates of our inequality measures and each country's fiscal position. As before, we control for distributional changes that result from faster or slower growth. Fourteen of the countries in our sample use the euro $(€)$ as their currency, while the rest retain their own currencies. Kinsella (2012) makes the salient point that fiscal consolidation in Ireland in the 1980s did not have the same deleterious effects on the economy as austerity recently, in part because Ireland's trade partners were growing and in part because of the devaluation of its currency. Neither channel was open to help offset austerity to any country relying on trade within Europe and on the euro in 2010. Hence, we control for eurozone membership using a dummy and also export performance (measured as the growth in exports compared to the growth in the relevant export markets).

Putting everything together, we perform a relatively straightforward panel data analysis that regresses the percent change in the inequality index, $\Delta G$, against the percent change in a country's fiscal position, $\Delta F$, while taking into account said controls, as shown in equation (6). Use of the euro is captured by $D^{\epsilon}$ while $X$ and $g$ control for export performance and growth respectively (they appear as lagged terms to avoid endogeneity). Estimations also control for country and time fixed effects using country and year dummies (not shown in results).

$$
\Delta G_{i t}=\alpha_{i}+\mu_{t}+\beta_{1} \Delta F_{i t}+\beta_{2} g_{i t-1}+\beta_{3} X_{i t-1}+\beta_{4} D_{i t}^{€}+u_{i t}
$$

The basic model is modified to take into account interactions between the eurozone dummy and $\Delta F$, and to allow for lagged effects of $\Delta F$ on the distribution. Given the sufficient length of the panel, we use Prais-Winsten estimation assuming panel-specific autocorrelated errors as suggested by Greene (2008) and Rabe-Hesketh/Skrondal (2012). The fact that the dependent variables are themselves estimates should not bias our coefficient estimates, but may be responsible for slightly inflated standard errors.

\section{DATA}

Data for the income shares used to estimate the underlying Lorenz curve model comes from the Statistics on Income and Living Conditions (SILC) database (European Commission 2015). We calculated pretax income shares for the bottom 4 percent, bottom 5 percent, every decile, the 1st and 3rd quartiles, and the bottom 95 percent, 96 percent, 98 percent, and 99 percent of households for every country. This gives us 18 coordinates to which we fit the Lorenz curve model (compared to 7 or 8 used in Schneider et al. 
2016). The resulting fit is exceptional for all countries and years, with reported values of $R^{2}$ exceeding 0.999 in all cases.

We take a very standard approach and use the change in cyclically adjusted primary balance (CAPB) as our primary proxy for austerity. Estimates for CAPB come from the IMF Fiscal Monitor data set (IMF 2015a). ${ }^{6}$ Guajardo et al. (2014) have made a compelling case that $\mathrm{CAPB}$ is an imperfect measure of austerity at best and is quite likely to result in an underestimation of the contractionary effects. We hope, however, that recent adjustments made by the IMF to exclude one-time spending (for example, in Ireland in 2010 in support of its banking sector) and the fact that we are looking at the distributional effects mitigates some of the worst biases of using this measure. As a complement, we offer an analysis that uses changes in the OECD's estimates for cyclically adjusted current distributions (CACD) net of interest payment and cyclically adjusted current revenue (CACR) instead of CAPB. The data for CACD, CACR, and export performance comes from the OECD Economic Outlook No 98 released November 2015. While looking at spending and revenue separately does not resolve the issues with CAPB, it does allow us to comment on which side of fiscal policy appears to be driving the distributional changes. Summary statistics for the variables used in our analysis are listed in Table 3.

As a way of comparing the different data sources for consistency, we show a comparison between the IMF Fiscal Monitor 2014 CAPB estimates versus the 2015 estimates, and the IMF CAPB estimate versus the difference between CACR and CACD in Figure 3. Clearly, the new and old CAPB estimates agree very well, and OECD and IMF data agree

\section{Table 3 Summary statistics}

\begin{tabular}{|c|c|c|c|c|c|}
\hline Variable & Mean & (Std dev.) & Min. & Max. & Notes \\
\hline Gini coefficient & 28.7 & $(3.69)$ & 22.4 & 38.1 & $\begin{array}{l}\text { Lorenz curve model } \\
\text { applied to SILC data }\end{array}$ \\
\hline$G_{0}$ & 40.3 & $(9.04)$ & 13.20 & 66.0 & $\begin{array}{l}\text { Lorenz curve model } \\
\text { applied to SILC data }\end{array}$ \\
\hline$G_{1}$ & 18.45 & $(3.04)$ & 12.86 & 26.7 & $\begin{array}{l}\text { Lorenz curve model } \\
\text { applied to SILC data }\end{array}$ \\
\hline Growth & 1.235 & $(3.42)$ & -14.26 & 10.49 & OECD data \\
\hline CAPB & -1.41 & $(3.43)$ & -13.23 & 4.72 & $\begin{array}{l}\text { Cyclically adjusted primary } \\
\text { balance; IMF FM data }\end{array}$ \\
\hline CACD & 42.2 & $(5.14)$ & 32.0 & 53.0 & $\begin{array}{l}\text { Cyclically adjusted current } \\
\text { disbursements (w/out } \\
\text { interest payments); } \\
\text { OECD data }\end{array}$ \\
\hline CACR & 43.6 & $(5.67)$ & 32.5 & 58.4 & $\begin{array}{l}\text { Cyclically adjusted current } \\
\text { revenue; OECD data }\end{array}$ \\
\hline Export performance & 0.036 & $(4.10)$ & -12.79 & 21.5 & $\begin{array}{l}\text { Export growth relative to } \\
\text { the growth in the rele- } \\
\text { vant export markets; } \\
\text { OECD data }\end{array}$ \\
\hline Euro & 0.64 & - & 0 & 1 & $\begin{array}{l}\text { Dummy indicating use of } \\
€ \text { or not }\end{array}$ \\
\hline
\end{tabular}

6. The only exception is Estonia, for which there is no CAPB estimate in the IMF database. We use the OECD CAPB estimate for Estonia instead. 

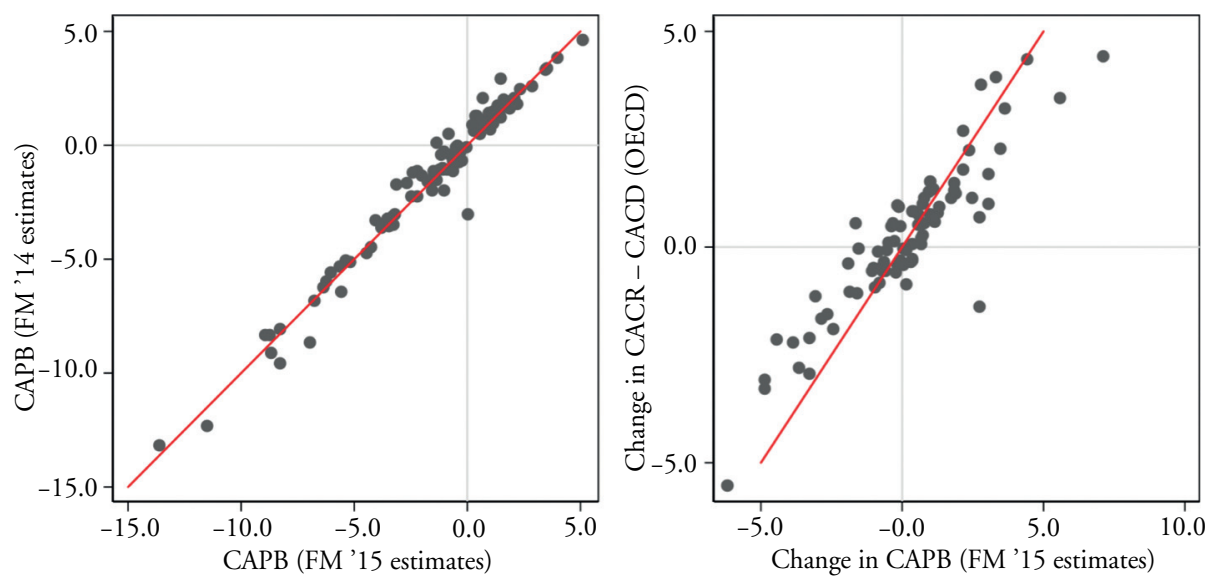

Figure 3 Comparing the 2014 and 2015 IMF CAPB data, and changes in CAPB vs changes in $O E C D$ revenue minus spending estimates

reasonably well as cyclically adjusted deficit proxies. There is some discrepancy between CAPB and (CACR-CACD), which makes sense because the 2015 IMF estimates take extraordinary care to drop one-time expenditures that are likely to still be included in the OECD estimates. ${ }^{7}$

A visual comparison of the estimated Gini and the JV indices presented in Schneider et al. (2016) and our revised estimates is shown in Figures 4 and 5. The new estimates of the $\mathrm{JV}$ indices match the old estimates well, while the estimated Gini coefficient is basically unaltered. It is not surprising that the estimates of $G_{0}$ and $G_{1}$ have changed somewhat given the additional data density in the crucial tail regions underlying their estimation. The overall correspondence between old and new estimates, however, gives us confidence that our original results were qualitatively correct. We explore the effect of the new data and new inequality estimates on the previous results explicitly in the Results section (5) of this paper.

A final note of warning is that CAPB, CACD, and CACR estimates are all expressed as percentages of potential GDP, which itself is an estimate based on filtered historical trends. As the crisis in many European countries is prolonged, statistical agencies are prone to making backwards revisions of their potential GDP estimates. Unfortunately, using these measures of countries' fiscal position for an analysis like ours makes the results sensitive to such revisions. We cannot rule out that even the switch from the slightly older IMF estimates used in our earlier work to the more up-to-date estimates might result in weakened results, but the side-by-side comparison of the estimates presented in Schneider et al. (2016) and the same analysis using the new data (see Appendix 1) reveals no important changes in the results. A more proper comparison to a historical dataset like the one constructed and used by Guajardo et al. (2014) would shed light on how sensitive our

7. The OECD also provides CAPB estimates, though these can deviate significantly from the IMF estimates. For example, the IMF estimates CAPB for Ireland in 2010 at -6.50 percent of potential GDP, while the OECD puts the same data point at -25.19 percent. The difference appears to be one-time banking sector support that the OECD includes but the IMF does not (IMF 2015b). 


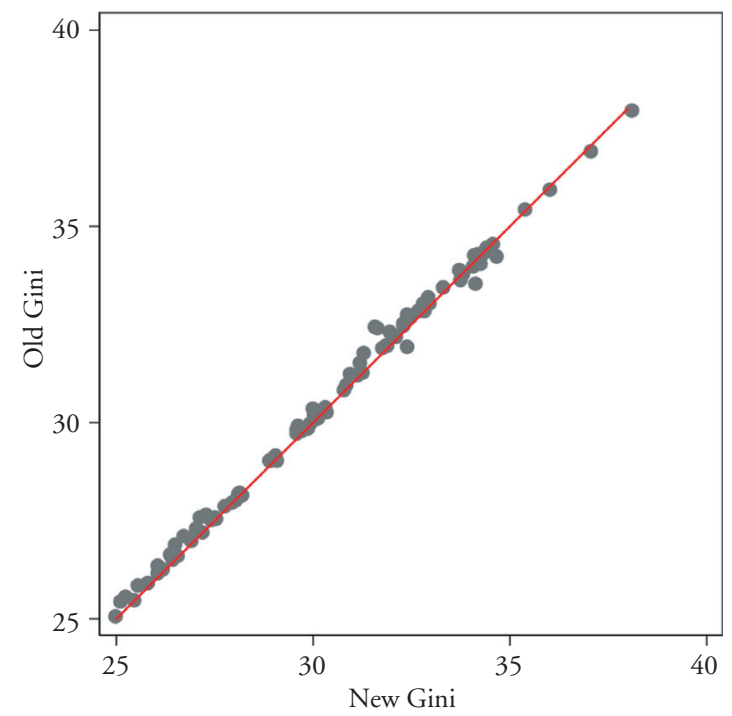

Figure 4 Comparing the old and new estimated Gini coefficients
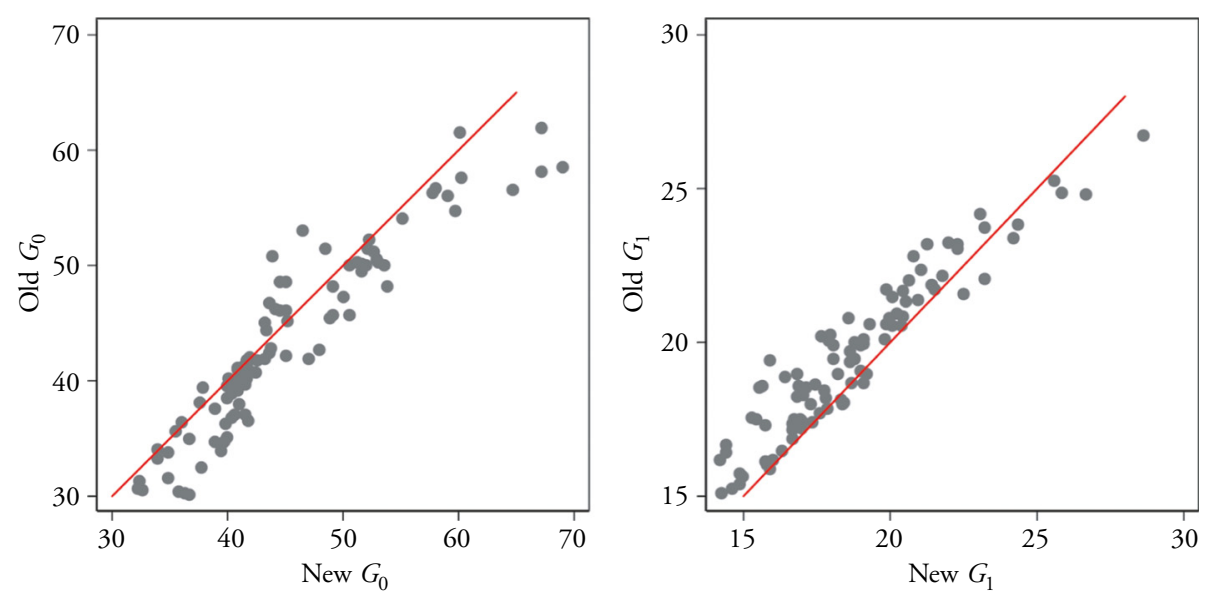

Figure 5 Comparing the old and new estimates of the JV indices

findings are to the choice of fiscal measures, but we currently do not have access to the appropriate data.

Another important improvement is the expanded list of countries for which this income data has become available. There are now 24 countries in our sample, which are listed in Table 4. Many of these countries saw a sharp increase in their cyclically adjusted primary deficit (increasingly negative CAPB) in the wake of the financial crisis as the result of sudden capital flight. Greece, Spain, Portugal, and Ireland received most of the attention from the press and European policy-makers, but this pattern is also seen in Belgium, Denmark, Finland, France, Iceland, the Netherlands, Poland, 
Table 4 Countries

\begin{tabular}{lcccc}
\hline Country & Gini in 2007 & CAPB in 2007 & Debt in 2007 & Currency \\
\hline Austria & 26.1 & -0.99 & 64.8 & $€$ \\
Belgium & 26.2 & 2.40 & 86.8 & $€$ \\
Czech Republic & 25.2 & -2.24 & 27.8 & koruna \\
Denmark & 25.2 & 3.88 & 27.3 & Danish krone \\
Estonia & 33.4 & -5.01 & 3.7 & $€$ \\
Finland & 26.1 & 1.71 & 34.0 & $€$ \\
France & 26.6 & -1.12 & 64.2 & $€$ \\
Germany & 30.3 & 1.62 & 63.8 & $€$ \\
Greece & 34.4 & -5.37 & 102.8 & $€$ \\
Hungary & 25.6 & -3.55 & 65.8 & forint \\
Iceland & 27.9 & 3.08 & 27.3 & króna \\
Ireland & 31.2 & -9.18 & 23.9 & $€$ \\
Italy & 31.9 & 1.68 & 99.7 & $€$ \\
Latvia & 35.5 & -0.78 & 7.2 & $€$ \\
Lithuania & 34.0 & -0.47 & 16.7 & $€$ \\
Luxembourg & 27.5 & 0.98 & 7.0 & $€$ \\
Netherlands & 27.6 & 1.21 & 45.3 & Norwegian krone \\
Norway & 23.6 & -7.27 & 49.2 & złoty \\
Poland & 32.2 & -0.26 & 44.6 & $€$ \\
Portugal & 36.9 & -1.56 & 68.4 & $€$ \\
Slovenia & 23.3 & -1.43 & 22.7 & (1.53 \\
Spain & 32.0 & 1.58 & 35.5 & Swedish krona \\
Sweden & 23.4 & 2.09 & 38.1 & $£$ \\
United Kingdom & 32.7 & -3.70 & 43.6 & \\
\hline
\end{tabular}

and the United Kingdom. ${ }^{8}$ It is this widespread increase in deficits that led to panic among policy-makers and the strong push for austerity in 2009.

Other countries in our sample do not follow this pattern. Sweden, for example, saw an increase in its primary surplus leading up to 2009 and Hungary aggressively decreased its primary deficit to end up with a small surplus by 2009. Austria, the Czech Republic, and Italy saw no notable deficit increase prior to 2009, although all three countries made strong moves towards surpluses post-2009. It turns out, while the impetus and push for austerity was widespread, it was not universal across Europe, thus providing a useful amount of variation for our panel analysis.

\section{RESULTS}

In this section we present the main results of our panel data analysis. First, we briefly explore the statistical relationship between growth and austerity suggested by our data set. Second, we show the results using the full set of countries and the expanded analysis window. An interesting new finding is that the relationship between austerity as measured by changes in CAPB and overall inequality weakens, while we recover a new significant

8. Unfortunately OECD CACD and CACR estimates are not available for Latvia and Lithuania, so they are not included in the regressions featuring a separation of spending and revenue adjustments. 
relationship between changes in the distribution towards the extremes and changes in cyclically adjusted revenue.

\subsection{Growth and austerity}

We want to briefly explore the strong negative correlation between growth and austerity found in our sample of countries. Listed in Table 5 are the results of some simple panel regressions. Even (A), a simple ordinary least squares (OLS) regression with clustered errors and no fixed effects, suggests a statistically significant negative relationship between austerity and growth. (B) is also an OLS regression but controls for fixed effects. (C) and (D) are Prais-Winston regressions assuming panel autocorrelated errors. Regardless of estimation technique, the negative relationship persists and is highly significant.

The results presented in Table 5 are hardly surprising given the numerous analyses that have found similar results. For example, researchers at the IMF found that the multipliers implicitly assumed by proponents of expansionary fiscal consolidation were too small (Blanchard/Leigh 2013), in part because they depend significantly on the state of the economy (Baum et al. 2012), implying that the contractionary effects were understated and the expansionary effects overemphasized in the case for austerity. Despite being critical of the IMF's cyclical adjustments, Perotti (2012) also concedes that austerity in Europe after the financial crisis was likely to be contractionary, echoing Kinsella (2012) on the role of currency adjustments ${ }^{9}$ and Eggertsson/Krugman (2012) regarding the limited room for interest rate adjustments (see also Botta 2016 for a recent discussion of the theoretical and empirical sides of this debate). Given the pro-growth bias of changes in CAPB documented by Guajardo et al. (2014), our results may even understate the negative effects. We now proceed to the analysis of how austerity has impacted the profile of inequality across the countries in our data.

Table 5 Panel regression results: growth and austerity

\begin{tabular}{lcccc}
\hline & $(\mathrm{A})$ & $(\mathrm{B})$ & $(\mathrm{C})$ & $(\mathrm{D})$ \\
\hline$\Delta \mathrm{CAPB}$ & $-0.26^{*}$ & $-0.35^{* *}$ & $-0.34^{* * *}$ & $-0.35^{* * *}$ \\
$€$ & $(0.135)$ & $(0.163)$ & $(0.084)$ & $(0.085)$ \\
& -0.76 & -0.157 & -0.114 & - \\
Exp. perf. & $(0.45)$ & $(0.112)$ & $(0.81)$ & - \\
$€ \times$ Exp. perf. & 0.027 & $0.161^{* * *}$ & $0.176^{* * *}$ & $0.21^{* * *}$ \\
& $(0.043)$ & $(0.039)$ & $(0.055)$ & $(0.035)$ \\
Constant & $0.36^{* * *}$ & 0.081 & 0.081 & - \\
& $(0.138)$ & $(0.085)$ & $(0.078)$ & - \\
& $1.17^{* * *}$ & $11.6^{* * *}$ & $10.6^{* * *}$ & $10.3^{* * *}$ \\
$R^{2}$ & $(0.36)$ & $(0.31)$ & $(2.9)$ & $(3.1)$ \\
Cntry. FEs & 0.147 & 0.78 & 0.80 & 0.80 \\
Year FEs & No & Yes*** & Yes*** & Yes*** \\
\hline
\end{tabular}

Notes: ${ }^{*} p<0.10,{ }^{* *} p<0.05,{ }^{* * *} p<0.02$; standard errors in parentheses; $N=177$.

9. What is surprising, given this literature, is that the correlation between growth and austerity does not seem to be conditional on a country's use of the $€$. 


\subsection{Expanded results}

We now estimate the comprehensive model to assess the relationship between austerity and inequality that not only controls for eurozone membership and export performance, but also includes interaction terms between the eurozone dummy and changes in CAPB (or changes in CACD and CACR when these replace CAPB). We also include lagged change terms that appear to be of statistical significance for some specifications. Where they are, they tend to indicate that the distributional effects of changes in CAPB (or CACD and CACR) are short-lived. The estimated coefficients based on the full model are listed in Table 6.

Note that the inclusion of export performance has resulted in the link between pastperiod growth and changes in the Gini disappearing. Growth now appears to only have

Table 6 Panel regression results

\begin{tabular}{|c|c|c|c|c|c|c|}
\hline \multirow[t]{2}{*}{ Dependent variable } & \multicolumn{2}{|c|}{ Gini } & \multicolumn{2}{|c|}{$G_{0}$} & \multicolumn{2}{|c|}{$G_{1}$} \\
\hline & (1) & (2) & (3) & (4) & (5) & (6) \\
\hline $\bar{€}$ & $\begin{array}{c}-0.25 \\
(1.20)\end{array}$ & $\begin{array}{c}1.41 \\
(1.75)\end{array}$ & $\begin{array}{c}2.04 \\
(2.53)\end{array}$ & $\begin{array}{l}4.37^{* *} \\
(2.12)\end{array}$ & $\begin{array}{c}3.52 \\
(3.90)\end{array}$ & $\begin{array}{c}1.45 \\
(4.36)\end{array}$ \\
\hline$\Delta \mathrm{CAPB}_{t}$ & $\begin{array}{c}-0.43^{* * *} \\
(0.13)\end{array}$ & - & $\begin{array}{l}-0.66^{* * *} \\
(0.20)\end{array}$ & - & $\begin{array}{c}-0.094 \\
(0.24)\end{array}$ & - \\
\hline$\Delta \mathrm{CAPB}_{t-1}$ & $\begin{array}{c}-0.34^{* * *} \\
(0.14)\end{array}$ & - & $\begin{array}{c}0.32^{*} \\
(0.18)\end{array}$ & - & $\begin{array}{c}-0.65^{* * *} \\
(0.22)\end{array}$ & - \\
\hline$€ \times \Delta \mathrm{CAPB}_{t}$ & $\begin{array}{l}0.77^{* * *} \\
(0.18)\end{array}$ & - & $\begin{array}{l}0.65^{\text {*** }} \\
(0.26)\end{array}$ & - & $\begin{array}{c}0.48 \\
(0.37)\end{array}$ & - \\
\hline$€ \times \Delta \mathrm{CAPB}_{t-1}$ & $\begin{array}{l}0.49^{* * *} \\
(0.21)\end{array}$ & - & $\begin{array}{c}-0.42 \\
(0.30)\end{array}$ & - & $\begin{array}{l}1.00^{* * *} \\
(0.41)\end{array}$ & - \\
\hline$\Delta \mathrm{CACD}_{t}$ & - & $\begin{array}{l}1.23^{\text {*** }} \\
(0.52)\end{array}$ & - & $\begin{array}{l}2.26^{* * *} \\
(0.80)\end{array}$ & - & $\begin{array}{c}-0.37 \\
(1.26)\end{array}$ \\
\hline$\Delta \mathrm{CACD}_{t-1}$ & - & $\begin{array}{c}0.58 \\
(0.56)\end{array}$ & - & $\begin{array}{c}-3.73^{* * *} \\
(0.81)\end{array}$ & - & $\begin{array}{l}3.02^{* * *} \\
(1.26)\end{array}$ \\
\hline$€ \times \Delta \mathrm{CACD}_{t}$ & - & $\begin{array}{c}-1.97^{* * *} \\
(0.51)\end{array}$ & - & $\begin{array}{c}-1.57^{*} \\
(0.82)\end{array}$ & - & $\begin{array}{c}-1.20 \\
(1.31)\end{array}$ \\
\hline$€ \times \Delta \mathrm{CACD}_{t-1}$ & - & $\begin{array}{c}-0.41 \\
(0.52)\end{array}$ & - & $\begin{array}{l}3.19^{* * *} \\
(0.91)\end{array}$ & - & $\begin{array}{c}-2.37^{*} \\
(1.23)\end{array}$ \\
\hline$\Delta \mathrm{CACR}_{t}$ & - & $\begin{array}{c}-1.98^{* * *} \\
(0.41)\end{array}$ & - & $\begin{array}{c}0.54 \\
(0.56)\end{array}$ & - & $\begin{array}{c}-3.61^{* * *} \\
(0.91)\end{array}$ \\
\hline$\Delta \mathrm{CACR}_{t-1}$ & - & $\begin{array}{c}-0.34 \\
(0.47)\end{array}$ & - & $\begin{array}{c}-0.37 \\
(0.65)\end{array}$ & - & $\begin{array}{c}0.14 \\
(1.06)\end{array}$ \\
\hline$€ \times \Delta \mathrm{CACR}_{t}$ & - & $\begin{array}{l}1.99^{* * *} \\
(0.55)\end{array}$ & - & $\begin{array}{c}0.16 \\
(0.55)\end{array}$ & - & $\begin{array}{l}2.73^{* *} \\
(1.21)\end{array}$ \\
\hline$€ \times \Delta \mathrm{CACR}_{t-1}$ & - & $\begin{array}{c}-0.051 \\
(0.57)\end{array}$ & - & $\begin{array}{l}0.00046 \\
(0.62)\end{array}$ & - & $\begin{array}{c}-0.50 \\
(1.24)\end{array}$ \\
\hline$g_{t-1}$ & $\begin{array}{c}0.098 \\
(0.14)\end{array}$ & $\begin{array}{c}-0.034 \\
(0.16)\end{array}$ & $\begin{array}{c}-0.56^{*} \\
(0.30)\end{array}$ & $\begin{array}{c}-0.50^{* *} \\
(0.23)\end{array}$ & $\begin{array}{c}0.50 \\
(0.35)\end{array}$ & $\begin{array}{c}0.23 \\
(0.40)\end{array}$ \\
\hline Exports $_{t-1}$ & $\begin{array}{c}-0.22^{* * *} \\
(0.082)\end{array}$ & $\begin{array}{c}-0.23^{* * *} \\
(0.075)\end{array}$ & $\begin{array}{l}0.62^{\text {*** }} \\
(0.18)\end{array}$ & $\begin{array}{l}0.66^{* * *} \\
(0.14)\end{array}$ & $\begin{array}{c}-0.65^{* * *} \\
(0.19)\end{array}$ & $\begin{array}{c}-0.69^{* * *} \\
(0.16)\end{array}$ \\
\hline Constant & $\begin{array}{l}1.35 \\
(4.51) \\
\end{array}$ & $\begin{array}{l}-2.33 \\
(1.56) \\
\end{array}$ & $\begin{array}{c}-7.41 \\
(9.13) \\
\end{array}$ & $\begin{array}{c}0.64 \\
(2.14) \\
\end{array}$ & $\begin{array}{c}-1.91 \\
(14.0) \\
\end{array}$ & $\begin{array}{c}-6.68^{*} \\
(3.84) \\
\end{array}$ \\
\hline$\overline{R^{2}}$ & 0.35 & 0.36 & 0.33 & 0.35 & 0.26 & 0.28 \\
\hline$N$ & 155 & 175 & 155 & 175 & 155 & 175 \\
\hline
\end{tabular}

Notes: ${ }^{*} p<0.10,{ }^{* *} p<0.05,{ }^{* * *} p<0.02$; standard errors in parentheses. 
a weak correlation with inequality at the bottom, where faster growth is associated with reduced inequality. One could argue that the weak correlation between inequality and growth is consistent with Dollar et al. (2015), while the negative association between inequality at the bottom and past growth is consistent in terms of direction with Voitchovsky (2005). However, our model indicates that causation runs from growth to inequality: faster growth leads to reduction in inequality at the bottom, not the other way around.

Past export performance appears to have a very strong relationship with distributional changes. Notably, strong export performance is associated with a rise in inequality at the bottom and reduced inequality at the top. Given that export sectors tend to be concentrated in manufacturing and services associated with tourism, it is not surprising that better export performance would differentially boost incomes at the lower end of the distribution. The finding that the effect at the top of the income distribution goes in the other direction remains to be explained.

Since we are primarily interested in the marginal effect of changes in CAPB, CACD, and CACR on our different measures of inequality, we show our estimates for them in Table 7. Concentrating on the statistically significant marginal effects, we found that across eurozone countries spending cuts (decreases in CACD) increased overall inequality. Specifically, they were associated with decreased inequality at the bottom as measured by $G_{0}$, but that decrease was more than offset by increased inequality at the top as measured by $G_{1}$. Some of these effects appeared to fade quickly as indicated by the reversal in sign on the lagged change in current distributions (never statistically significant). Also not significant - but largely complimentary in signs - were the distributional effects of revenue increases. A positive change in current revenue was associated with higher inequality at the bottom and overall, but lower inequality in every measure next period.

The effects of changes in spending and revenue are very different for the countries not in the eurozone. Here, the effect of spending cuts on inequality at the bottom appears to trump the inequality-increasing effect at the top to produce a statistically significant overall reduction in the Gini. The offsetting next-period effects on both $G_{0}$ and $G_{1}$ are statistically significant, so that the next-period effect on overall inequality is likely muted. Revenue increases have statistically more distinct effect on top incomes and even the effect on overall inequality is significant.

These results are broadly consistent with Schneider et al. (2016): a policy turn towards austerity appears to drive up overall inequality among eurozone countries via greater inequality among high incomes. We see in addition that this is driven primarily by

Table 7 Marginal effects summary

\begin{tabular}{|c|c|c|c|c|c|c|}
\hline & \multicolumn{2}{|c|}{$\triangle \mathrm{CAPB}$} & \multicolumn{2}{|c|}{$\triangle \mathrm{CACD}$} & \multicolumn{2}{|c|}{$\triangle \mathrm{CACR}$} \\
\hline & $t$ & $t-1$ & $t$ & $t-1$ & $t$ & $t-1$ \\
\hline \multicolumn{7}{|c|}{ Eurozone countries } \\
\hline Gini & $0.34^{* * *}$ & 0.155 & $-0.74^{* * *}$ & 0.168 & 0.0155 & -0.39 \\
\hline$G_{0}$ & -0.167 & -0.102 & $0.69^{*}$ & -0.55 & 0.70 & -0.37 \\
\hline$G_{1}$ & 0.38 & 0.35 & $-1.57^{* * *}$ & 0.65 & -0.88 & -0.36 \\
\hline \multicolumn{7}{|c|}{ Other countries } \\
\hline Gini & $-0.43^{* * *}$ & $-0.34^{* * *}$ & $1.23^{* * *}$ & 0.58 & $-1.98^{* * *}$ & -0.34 \\
\hline$G_{0}$ & $-0.66^{* * *}$ & $0.32^{*}$ & $2.3^{* * *}$ & $-3.7^{* * *}$ & 0.54 & -0.37 \\
\hline$G_{1}$ & -0.094 & $-0.65^{* * *}$ & -0.37 & $3.0^{* * *}$ & $-3.6^{* * *}$ & 0.139 \\
\hline
\end{tabular}

Notes: ${ }^{*} p<0.10,{ }^{* *} p<0.05,{ }^{* * *} p<0.02$. 
changes in public expenditures. Among countries not using the euro as their currency, austerity tends to reduce inequality, though that reduction is driven by reduced inequality among low incomes, a finding that is directionally consistent with the findings for the eurozone countries. While changes in current expenditures are important across country groups, changes in current revenue only have statistically significant effect for non-eurozone countries. Raising more revenue appears to reduce inequality at the top and thus inequality overall.

To get some feel for the context of our results, it is illustrative to look at the average changes in spending and revenue. Both countries on the euro and countries maintaining their own currency sharply cut spending on average after 2010, as indicated by the steep decline in CACD in both panels of Figure 6. The difference is that eurozone countries had maintained fairly constant spending levels prior to 2008, interrupted by a rise in CACD between 2008 and 2009 that indicated a fiscal response to the unfolding financial crisis. By contrast, the non-eurozone countries had been ratcheting up spending for a number of years before and through the crisis. Moreover, they maintained steady revenue growth, so that deficits did not explode as they did for the eurozone.

The left panel of Figure 6 shows the collapse in revenues across the eurozone as a result of the financial crisis. As Guajardo et al. (2014) have pointed out, cyclical adjustments are generally imperfect and in particular do not capture revenue collapse due to a sharp drop in asset prices and the subsequent loss of capital gains taxes. The sharp decline in CACR prior to the rise in CACD - and the modest magnitude and short duration of the latter supports the conclusion drawn by Boyer (2012) and Zezza (2012) that the rapid rise in deficits across much of Europe was the symptom of the financial crisis and not of profligate spending. Nonetheless, Figure 6 clearly shows all countries on average cutting spending and increasing revenue to fight structural deficits starting in 2010. In addition to the contractionary effects on the European economy overall, we document that this is likely to have reduced inequality at the bottom of the distribution of income in each country and sharply increased inequality at the top in the eurozone.

For non-eurozone countries, we find evidence that austerity reduced inequality on the whole for two reasons. The decrease in inequality at the bottom appears to dominate and we find no evidence (the coefficient estimate is near zero) for an increase in inequality at the top. Part of the story also appears to be the accelerated rise in CACR seen in the right panel of Figure 6. The panel regression results shown in Table 7 indicate that for countries not on the euro, changes in CACR played a big role in reducing inequality at the top.

Obviously, these are broad generalities and do not speak to the particular policy changes in each country. The distributional effects we are trying to characterize are

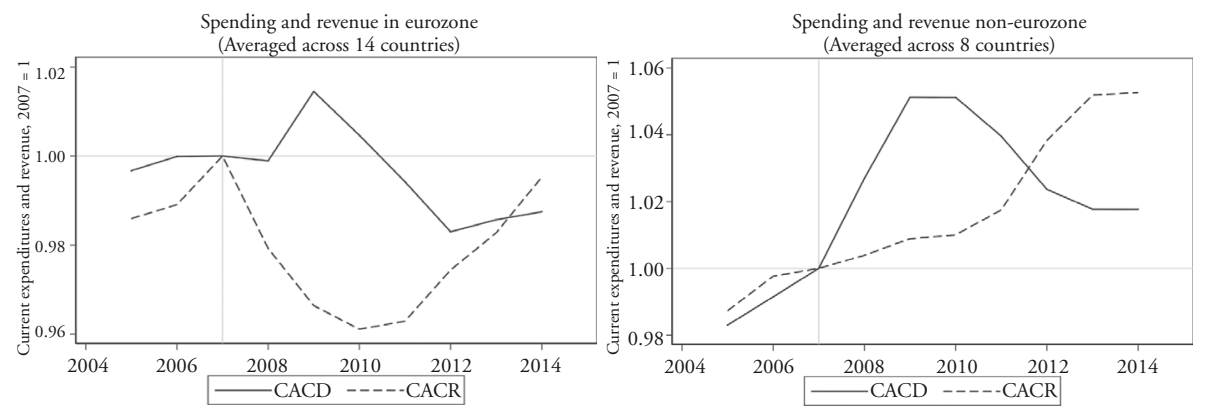

Figure 6 Eurozone and non-eurozone spending and revenue 
very likely to be sensitive to what programs are cut or how additional revenue is raised. In that sense, the amount of residual variation that makes many of our estimates appear insignificant is not surprising.

\section{DISCUSSION}

We return to Voitchovsky (2005), who argued it is 'the profile of inequality' that matters for the future performance of an economy. In this paper, we presented two additional indices that help assess changes in the profile of inequality by capturing inequality at the top and bottom of the income distribution separately. The JV indices (along with the Gini coefficient) were estimated for 24 European countries over 9 years covering the policy turn toward austerity.

For the eurozone, we find an exacerbated effect of austerity on inequality as countries implemented spending cuts that effectively reduced inequality at the bottom while increasing it at the top. Other European Union countries that maintained their independent currencies were more able to deflate without cutting wages as sharply, partially explaining why they saw a reduction in income inequality. While we have uncovered new correlative relationships between austerity and distributional changes, adding significant nuance to the existing literature, further work is warranted to explore the exact causal pathways between contractionary fiscal policy post-crisis and rising inequality. A systematic country-by-country comparison of changes in the profile of inequality brought out by the JV indices to detailed information about policy changes and their timing provided by the IMF country reports, for example, would shed a lot more light on how specific implementations of austerity affected the distribution of income.

To speculate a little, inequality does represent an incentive structure of some sort, though care must be taken to understand what behavior is being incentivized. In so far as income from work (labor) dominates the bottom of the distribution, inequality at the bottom is perhaps most associated with increasing rewards for productive work. High inequality at the bottom implies that local moves up yield relatively big rewards in terms of extra share in total income going to the household able to make such a move, and local moves (for example, between adjacent quintiles) tend to be most common. But higher inequality at the bottom also means that those left behind receive a smaller share of total income, and whether that is socially acceptable depends on the effectiveness and cost of the social safety net for protecting the most vulnerable. In the age of austerity, it is of course exactly the social safety net that has been the prime target of spending cuts.

Conversely, a lack of inequality at the bottom means that the vast majority of households have no real incentives to move up, because increases in productivity through education, training, or hard work reap only small additional rewards. In a time of lackluster growth - or explicit contraction for many European countries - lower inequality at the bottom probably means a broadly shared loss of resources and deterioration of incentives. Following public sentiment in Europe, it does seem that it is austerity leading to reduced inequality at the bottom and a weakened safety net that explains the popular dissatisfaction that is shaping politics.

By contrast, inequality at the top reflects an incentive structure that applies only to a small elite of income earners. If suspicions are born out that a substantial portion of these incomes reflect rent-seeking, then more inequality at the top actually implies increased incentives to misbehave (Stiglitz 2012; 2016). The combination of stagnation and a falling wage share, together with low inequality at the bottom while inequality at the top is rising, surely presents worrisome implications. 
If the policy agenda behind austerity is motivated by tapping the potential of markets to ensure efficiency, then the desired result should be to increase inequality at the bottom while providing due safeguards for the very bottom - and limiting inequality at the top to deincentivize rent-seeking. Our results imply the opposite: that on average austerity reduced the incentives for most workers while only the incentives for the elite at the very top increased.

\section{ACKNOWLEDGEMENT}

We thank Mark Blyth for the suggestion of controlling for export performance and the positive feedback that he gave us on an early version of this work. We are also grateful to our discussants at the 19th IMK/FMM conference and the 2016 EEA meetings. Their kind comments helped improve this work; we, of course, own all errors that remain.

\section{REFERENCES}

Atkinson, A.B. (1970): On the measurement of inequality, in: Journal of Economic Theory, 2, 244-263.

Atkinson, A.B., Piketty, T., Saez, E. (2011): Top incomes in the long run of history, in: Journal of Economic Literature, 49, 3-71.

Baum, A., Poplawski-Ribeiro, M., Weber, A. (2012): Fiscal multipliers and the state of the economy, IMF Working Paper, 286, URL: http://ssrn.com/abstract=2202637.

Blanchard, O., Leigh, D. (2013): Growth forecast errors and fiscal multipliers, IMF Working Paper, 1301.

Blyth, M. (2013a): Austerity as ideology: a reply to my critics, in: Comparative European Politics, 11, 737-751, URL: http://dx.doi.org/10.1057/cep.2013.25.

Blyth, M. (2013b): The austerity delusion: why a bad idea won over the West, in: Foreign Affairs, $92,41-56$.

Botta, A. (2016): The theoretical weaknesses of the expansionary austerity doctrine, Working Paper No 34, Greenwich Papers in Political Economy, Greenwich Political Economy Research Center, London.

Bougrine, H. (2012): Fiscal austerity, the great recession and the rise of new dictatorships, in: Review of Keynesian Economics, 1, 109-125.

Boyer, R. (2012): The Four Fallacies of contemporary austerity policies: the lost Keynesian legacy, in: Cambridge Journal of Economics, 36, 283-312.

Dollar, D., Kleineberg, T., Kraay, A. (2015): Growth, inequality, and social welfare: cross-country evidence, in: Economic Policy, 30, 335-377.

Eggertsson, G.B., Krugman, P. (2012): Debt, deleveraging, and the liquidity trap: a Fisher-Minsky-Koo approach, in: The Quarterly Journal of Economics, 127, 1469-1513.

European Commission (2015): Statistics on income and living conditions (SILC), URL: http://ec. europa.eu/eurostat/web/income-and-living-conditions/overview (accessed 11 December 2015).

Ginn, J. (2013): Austerity, inequality and politics, in: RASP - Research on Ageing and Social Policy, 1, $28-53$.

Gordon, R.J., Dew-Becker, I. (2007): Selected issues in the rise of income inequality, in: Brookings Papers on Economic Activity, 2007, 169-190.

Greene, W.H. (2008): Econometric Analysis, 6th edn, Upper Saddle River, NJ: Pearson Prentice Hall.

Guajardo, J., Leigh, D., Pescatori, A. (2014): Expansionary austerity? International evidence, in: Journal of the European Economic Association, 12, 949-968.

IMF (International Monetary Fund) (2012): IMF fiscal monitor - taking stock: a progress report on fiscal adjustment, October, URL: http://www.imf.org/external/pubs/ft/fm/2014/01/fmindex. htm (accessed 21 February 2015). 
IMF (International Monetary Fund) (2014): IMF fiscal monitor - public expenditure reform: making difficult choices, April, URL: http://www.imf.org/external/pubs/ft/fm/2014/01/data/fmdata. xlsx (accessed 12 August 2016).

IMF (International Monetary Fund) (2015a): IMF fiscal monitor - database, October, URL: data. imf.org (accessed 16 January 2016).

IMF (International Monetary Fund) (2015b): IMF fiscal monitor - the commodities roller coaster: a fiscal framework for uncertain times, October, URL: http://www.imf.org/external/pubs/ft/fm/ 2014/01/fmindex.htm (accessed 21 February 2015).

Jantzen, R.T., Volpert, K. (2012): On the mathematics of income inequality: splitting the Gini index in two, in: The American Mathematical Monthly, 119, 824-837.

Jenkins, S.P. (2009): Distributionally-sensitive inequality indices and the GB2 income distribution, in: The Review of Income and Wealth, 22, 392-398.

Kinsella, S. (2012): Is Ireland really the role model for austerity?, in: Cambridge Journal of Economics, $36,223-235$.

Krugman, P. (2010): The opinion pages: myths of austerity, in: The New York Times, 1 July, URL: http://nyti.ms/1or9hkg.

Mankiw, N.G. (2013): Defending the one percent, in: The Journal of Economic Perspectives, 27, $21-34$.

OECD (Organisation for Economic Co-operation and Development) (2015): Economic Outlook, No 98, November, URL: data.oecd.org (accessed 15 December 2015).

Ortiz, I., Cummins, M. (2013): The age of austerity: a review of public expenditures and adjustment measures in 181 countries, Initiative for Policy Dialogue and the South Centre Working Paper, March.

Peet, R. (2011): Inequality, crisis and austerity in finance capitalism, in: Cambridge Journal of Regions, Economy, and Society, 4, 383-399.

Perotti, R. (2012): The 'austerity myth': gain without pain?, in: Alesina, A., Giavazzi, F. (eds), Fiscal Policy after the financial Crisis, Chicago: University of Chicago Press, 307-354.

Piketty, T., Saez, E. (2003): Income inequality in the United States, 1913-1998, in: Quarterly Journal of Economics, 118, 1-39.

Piketty, T., Saez, E. (2006): The evolution of top incomes: a historical and international perspective, in: American Economic Review, 96, 200-205.

Rabe-Hesketh, S., Skrondal, A. (2012): Multilevel Longitudinal Modeling Using Stata, 3rd edn, College Station, TX: Stata Press.

Rada, C., Kiefer, R. (2015): Distribution-utilization interactions: a race-to-the-bottom among OECD countries, in: Metroeconomica, Early View, doi: 10.1111/meca.12081.

Sarabia, J.-M., Castillo, E., Slottje, D.J. (1999): An ordered family of Lorenz curves, in: Journal of Econometrics, 91, 43-60.

Schaltegger, C.A., Weder, M. (2014): Austerity, inequality and politics, in: European Journal of Political Economy, 35, 1-22.

Schneider, M.P.A., Tavani, D. (2016): A tale of two Ginis in the US, 1921-2012, in: International Review of Applied Economics, 30, 677-692.

Schneider, M.P.A., Kinsella, S., Godin, A. (2016): Redistribution in the age of austerity: evidence from Europe 2006-2013, in: Applied Economics Letters, available online at URL: http://dx.doi. org/10.1080/13504851.2016.1221030.

Shorrocks, A.F. (1983): Ranking income distributions, in: Economica, 50, 3-17.

Solow, R., Mankiw, N.G., Burkhauser, R.V., Larrimore, J. (2014): The one percent, in: The Journal of Economic Perspectives, 28, 243-247.

Stiglitz, J.E. (2012): The Price of Inequality, New York: W.W. Norton.

Stiglitz, J.E. (2016): New theoretical perspectives on the distribution of income and wealth among individuals, in: Basu, K., Stiglitz, J.E. (eds), Inequality and Growth: Patterns and Policy, Vol. 1: Concepts and Analysis, New York: Palgrave Macmillan, 1-71.

Stockhammer, E. (2013): Why have wage shares fallen? A panel analysis of the determinants of functional income distribution, International Labor Office, Conditions of Work and Employment Series. 
Voitchovsky, S. (2005): Does the profile of income inequality matter for economic growth?, in: Journal of Economic Growth, 10, 273-296.

Zezza, G. (2012): The impact of fiscal austerity in the eurozone, in: Review of Keynesian Economics, $1,37-54$.

\section{APPENDIX 1 REPLICATION OF PREVIOUS RESULTS}

Repeating the analysis presented in Schneider et al. (2016), using the new estimates for the inequality measures and using the updated CAPB estimates, results in comparable point estimates for the coefficients (see Table A1). Standard error estimates, however, turned out to be slightly larger on average, though this does not affect the statistical significance of any of the estimates. Note that past growth appears to have a robust inequality-reducing effect by specifically driving down inequality at the bottom. For the panel covering the subset of 12 eurozone countries used in the initial study, changes in $\mathrm{CAPB}$ are associated with increased inequality driven by increased inequality at the top (note large positive coefficient on $\Delta$ CAPB for $\Delta G_{1}$ ). Just as in Schneider et al. (2016), the coefficients on $\Delta \mathrm{CAPB}$ for the $\Delta G_{0}$ regressions are negative, but not significant. We update the estimation technique to Prais-Winston with panel-specific autocorrelated errors and include export performance as an additional control. The 'PW OLS' columns in Table A1 show that neither changed the qualitative result for the original panel of countries, although some coefficients appear more significant and $R^{2}$ was higher.

Table A1 Panel regression results: replication of original results

\begin{tabular}{|c|c|c|c|c|c|c|c|c|c|}
\hline \multirow{2}{*}{$\begin{array}{l}\text { Dependent } \\
\text { variable }\end{array}$} & \multicolumn{3}{|c|}{$\Delta$ Gini } & \multicolumn{3}{|c|}{$\Delta G_{0}$} & \multicolumn{3}{|c|}{$\Delta G_{1}$} \\
\hline & Old & New & $\begin{array}{l}\text { PW } \\
\text { OLS }\end{array}$ & Old & New & $\begin{array}{l}\text { PW } \\
\text { OLS }\end{array}$ & Old & New & $\begin{array}{l}\text { PW } \\
\text { OLS }\end{array}$ \\
\hline$\overline{\triangle \mathrm{CAPB}}$ & $\begin{array}{c}0.36^{* * *} \\
(0.097)\end{array}$ & $\begin{array}{l}0.38^{* * *} \\
(0.12)\end{array}$ & $\begin{array}{l}0.50^{* * *} \\
(0.13)\end{array}$ & $\begin{array}{c}-0.44 \\
(0.27)\end{array}$ & $\begin{array}{c}-0.33 \\
(0.35)\end{array}$ & $\begin{array}{c}-0.36 \\
(0.26)\end{array}$ & $\begin{array}{l}1.10^{* * *} \\
(0.35)\end{array}$ & $\begin{array}{c}0.81^{*} \\
(0.42)\end{array}$ & $\begin{array}{l}0.96^{* * *} \\
(0.36)\end{array}$ \\
\hline Growth & $\begin{array}{c}-0.24^{*} \\
(0.108)\end{array}$ & $\begin{array}{c}-0.26^{*} \\
(0.13)\end{array}$ & $\begin{array}{l}-0.27^{* *} \\
(0.13)\end{array}$ & $\begin{array}{l}-0.91^{* *} \\
(0.31)\end{array}$ & $\begin{array}{l}-0.75^{* * *} \\
(0.26)\end{array}$ & $\begin{array}{l}-0.83^{* * *} \\
(0.29)\end{array}$ & $\begin{array}{c}0.132 \\
(0.38)\end{array}$ & $\begin{array}{c}0.16 \\
(0.35)\end{array}$ & $\begin{array}{c}0.16 \\
(0.36)\end{array}$ \\
\hline Exp. perf. & - & - & $\begin{array}{c}-0.018 \\
(0.096)\end{array}$ & - & - & $\begin{array}{c}0.41^{*} \\
(0.21)\end{array}$ & - & - & $\begin{array}{c}-0.18 \\
(0.25)\end{array}$ \\
\hline Constant & $\begin{array}{c}3.4^{*} \\
(1.85)\end{array}$ & $\begin{array}{c}2.56 \\
(1.63)\end{array}$ & $\begin{array}{l}2.71^{* * *} \\
(0.86)\end{array}$ & $\begin{array}{l}9.9^{* * *} \\
(2.7)\end{array}$ & $\begin{array}{c}5.36^{*} \\
(2.90)\end{array}$ & $\begin{array}{l}6.15^{* * *} \\
(1.90)\end{array}$ & $\begin{array}{c}0.30 \\
(4.7)\end{array}$ & $\begin{array}{l}-0.059 \\
(3.96)\end{array}$ & $\begin{array}{l}0.020 \\
(2.08)\end{array}$ \\
\hline$R^{2}$ & 0.18 & 0.21 & 0.35 & 0.29 & 0.23 & 0.35 & 0.24 & 0.18 & 0.27 \\
\hline
\end{tabular}

Notes: ${ }^{*} p<0.10,{ }^{* *} p<0.05,{ }^{* * *} p<0.02$; standard errors in parentheses; $N=84$. 